\title{
Ethics of Care in Practice: An Observational Study of Interactions and Power Relations between Children and Educators in Urban Ontario Early Childhood Settings
}

\author{
Rachel Langford and Brooke Richardson
}

\begin{abstract}
Rachel Langford is a professor in the school of early childhood studies at Ryerson University. She is the principal investigator of an SSHRC-awarded project that seeks to theorize and frame a robust and coherent integration of care, ethics of care, and care work into Canadian childcare advocacy, policy, and practice. She is a co-editor of an edited volume, Caring for Children: Social Movements and Public Policy in Canada (UBC Press), and the editor of an anthology, Theorizing Feminist Ethics of Care in Early Childhood Practice: Possibilities and Dangers (Bloomsbury Academic Press).

Email: rlangfor@ryerson.ca
\end{abstract}

Brooke Richardson is a postdoctoral fellow in the department of sociology at Brock University. She is currently working on an SSHRCfunded project examining the increasing privatization of childcare in Canada and editing a forthcoming anthology, Mothering on the Edge: A Critical Examination of Mothering within the Child Protection System (Demeter Press).

Email: brichardson@brocku.ca

This article explores observations of care practices in interactions between early childhood educators and children in two urban early childhood settings in Ontario. Analysis of these care practices is informed by a feminist ethics of care. Findings show that the care actions of educators were more often instrumental in nature, often incomplete, and/ or interrupted. Children's experience with and perspectives on their care were not taken into consideration. Structural factors such as staffing levels appeared to interfere significantly with the possibility of care as conceptualized from a feminist ethics of care framework. Practice and policy implications for the absence and presence of an ethics of care in Canadian early childhood settings are discussed.

Key Words: care; ethics of care; early childhood education; observation study
Dominant discourses around care and care workers in Canadian early childhood programs conceptualizes care as instrumental ${ }^{1}$ and carried out by women with a "natural" propensity for the work. The idea that care is "natural" to women (increasingly, poor and racialized women) has undermined, and continues to undermine, its social and economic value while situating it as immune to change. At the same time, dominant conceptualizations of care work in early childhood programs are relegated to outcome-based activities and interactions instrumentally addressing children's immediate physical and social needs. These discourses and understandings contribute to care's taken-for-granted nature, with care often taking place in the private sphere, and systematic devaluation in the formal market economy (Daley, 2012). Ironically, "care is so fundamental to our capacity to live together that we simply cannot see its significance and it becomes possible to ignore it" (Barnes, 2012, p.3).

The marginalization/occlusion of care work is particularly poignant in early childhood education (ECE), where the contemporary trend in most Western, English-speaking nations (e.g., Canada, the US, the UK, Australia, and New Zealand) has been to separate care and education policy and provision. One problematic consequence has been the inferior positioning of care relative to education in early childhood programs. The widespread belief that care work carried out in ECE programs comes "naturally" to women legitimizes its subordination and glosses over the inherent complex, messy, contextual, and emotional nature of working with young children. Instead, the primary path to professionalization in the field has been to focus on technocratic, standardized teaching and "learning" discourses distancing the profession from care (Langford, 2019). 
From an ethics of care perspective, the ability to navigate and respond to the complexities of care is precisely what makes work in early childhood settings both challenging and valuable. Joan Tronto's (2013) articulation of the four phases of care are helpful in identifying the complex processes of caring well for others through an ethics of care lens. These phases are: caring about (discerning a need), caring for (accepting responsibility), caregiving (the practice of giving care), and care-receiving (response from person receiving care). It is important to highlight the final phase, which requires active participation, acknowledgment, or feedback from the person receiving the care. This phase of care positions children as simultaneously dependent and agentic whereby the unequal power relationships between children and educators become a focal point of care practice. Drawing on Tronto (2013, p. 21), we see these care practices nested within other caring practices that create complex care interrelationships within (un)caring institutions and democracies.

We are not alone in attempting to reposition care as central to children's and educators' experiences of early childhood programs. Other scholars have attempted to bridge the care/education divide through proposing new terms in which "care" and "education" are more closely linked. Examples include "educare" (Löefdahl \& FolkeFichtelius, 2015; Van Laere \& Vanbenbroeck, 2016), "care-full pedagogy” (Luff \& Kanyal, 2015), and "relational pedagogy" (Papatheodorou, 2009). In contrast, while noting that care is an important concept for its "ethical nature," Peter Moss (2017) maintains "we should not encourage a view that 'care' is of exclusive or even particular relevance to young children by including it in the term we use to describe the field" (p. 13). On this basis, Moss prefers the term "early childhood education."

We agree with Moss that care is inherent in all education. However, we maintain it is particularly relevant to early childhood programs for two reasons. First, we argue that a denial of young children's particular need for care (extended to include their bodies, emotions, and minds) reduces children to a negative view of dependency (Gilson, 2014). We do not regard children's need for care as a limitation or deficit. As Erinn Gilson states, "the valorization of independence and self-sufficiency [in Western contexts] both reduces care to a means to an end (that of independence) rather than a value in itself and renders dependence incompatible with dignity" (2014, p. 9). We view needing care as a normal aspect of the human condition, necessary for human flourishing and wellbeing (Sevenhuijsen, 1998). On this basis, we see the early childhood setting as a site of "inevitable dependence and inextricable interdependence" (Kittay, 2015, p. 57) whereby ethical care practices are central to the work of early childhood educators.

However, we resist the idea that children are passive, helpless recipients of care. On the contrary, we assert that when power relations are acknowledged and explored within the context of care relations, and as an ethics of care insists, children are then placed in a greater position of competency. Mediated also by context, children can become active participants in their own (and others') care. We agree with Virginia Held (2006) that care relations are always embedded in social and historical contexts of power, which have profound effects on how care needs are interpreted and responded to by caregivers (p. 46). Without an appreciation of an ethics of care, one effect is that care receivers, which includes children, are denied participation in their own care as competent social agents. Therefore, an ethics of care in early childhood education requires more complex understandings of children's needs and more complex educator responses to them, and the presence and absence of children's responses to the care given.

Second, when we do not give particular relevancy to care in early childhood education, we deny the chronic exploitation of early childhood educators whose work is grounded in care. Advanced industrialized societies have only recently created a class-based system of care in which care work (once done by women now in the workforce) is carried out by poor, racialized, and female early childhood educators (Tronto, 2013). Because of overarching 
exploitative conditions, the ability of early childhood educators (henceforth educators) to engage in ethical caring relations is compromised. Their work is taken for granted and made invisible amid market mechanisms that overtly deny the value of their work. Thus, the power relations occurring within early childhood settings are complicated: it is not only the power relations between children (whose participation in care relations is often involuntary) and educators that are important to critique but also the power relations between the educators and those responsible for constructing the class-based system of care. In this way, educators are simultaneously powerful in their interactions with children but powerless in the context of a care economy that sidelines the value of care work. From our perspective, it is therefore important to name, critically research, and analyze care and care work in early childhood settings from an ethics of care framework.

The purpose of our observational study was to identify and describe the complexities of care with attention to how power relations play out in care practices in early childhood programs. An ethics of care orientation, specifically Tronto's (2013) identification of the process-oriented phases of caring, provides the tools to do this. Through our observations, we attempt to give real substance to care as a relational and ethical practice and to appreciate, document, and communicate the complexities of care relations beyond a "naturalized," gendered discourse. Applying a feminist ethics of care analysis to our observations of care practices seeks to name the exploitative and oppressive conditions under which care relations and care work currently operate in early childhood settings. In this way, the seemingly impermeable wall of "naturalized" care can begin to be dismantled.

\section{Theoretical framework: Feminist ethics of care}

Ethics of care is feminist in its history and orientation, arising out of a validation of women's moral experiences with caring for others (Held, 2006). Ethics of care critically analyzes the existing discourses, politics, and state systems whereby care work is allocated to women and racialized groups (Tronto, 2013). As Marian Barnes, Tula Brannelly, Lizzie Ward, and Nicki Ward write,

The critical feminist political position in which care ethics is based makes it more than a set of characteristics for the pursuit of good; it is a broad set of theories for the pursuit of justice that require actions within political and institutional systems as well as within interpersonal caring relationships. (2015, p. 12)

We assert that an ethics of care is still a contemporary and valuable framework because care remains so central to people's lives. As Tronto (2015) notes, care is at the core of power and politics: "Care is always infused with power. And this makes care deeply political" (p. 9). We maintain that there is something profound and political about how children and educators experience care (or not) in ordinary encounters, all day, every day. These experiences are the crux of children's and educators' well-being. Our study is, therefore, decidedly humanist. The ethics of care, with its focus on the complex processes of care and power as a practice and its insights into the systematic devaluing of care at a societal and political level, provides one means to identify and assert the value of caring well in early childhood settings.

Care ethics begin with the claim that "relations of interdependence and dependence are a fundamental feature of our existence" (Robinson, 2011, p. 4). Within these social relations, Maurice Hamington (2015) describes caring as "a series of actions, some large and explicit actions and some small and subtle actions that inform the quality of a relationship [over time], thus making it caring" (p. 280). In other words, care is revealed only through social relations (Randall, 2018). Hamington further distinguishes between care as virtue and care as action to emphasize that care is a concrete practice or activity experienced physically, emotionally, and/or intellectually by both a caregiver and care receiver. This means that while holding caring values is necessary, such values are insufficient 
for care as a practice, because it is through action that we know and realize caring (Hamington, 2015, p. 689). Nel Noddings (2015) also makes a distinction between what she calls caregiving and caring for, maintaining that "caregiving is an important element in care ethics, but, as a set of activities or occupations, it can be done with or without caring" (p. 73). We also offer a clarification: It may seem as if our focus is on two distinct categories, the caregiver and the care receiver. However, we see people, including children, always engaged in an "infinite spiral of relationships" (Kittay, 2001, quoted in Barnes, Brannelly, Ward, \& Ward, 2015, p. 16) as both givers and receivers of care in multiple contexts.

To practice care as conceptualized here is to decide to act in a caring way in response to the needs of another, recognizing inherent power imbalances and the broader context in which the practice is embedded. To act with care is therefore an ethical decision, involving critical reflection on the caring action (Dahlberg \& Moss, 2005). Critical reflection involves an evaluation or judgment about whether the processes of care ethics are present or absent. These processes are dynamic, contextual, nuanced, complex, and qualitatively different from one interaction to another (Engster \& Hamington, 2015). As Veronica Pacini-Ketchabaw, Fikile Nxumalo, Laurie Kocher, Enid Elliot, and Alejandra Sanchez (2015) state, an ethics of care calls for more than just a technical code of ethics; it "calls for total engagement of heart, mind, and spirit in intensely relational encounters" (p. 173).

Although the processes of care often overlap in messy ways, Tronto (2013) begins the relational encounter with the caring person "caring about" another's needs. The caring educator then enters a caring interaction, noticing and attending to expressed needs. Entangled in this recognition is a sense of responsibility, an openness to personal disruption, particular caring values and motives, an other-directed disposition or attitude, the imagination that the care can have an effect, and sensitivity to the particular context of children's needs, ideas, interests, goals, and concerns (Hamington, 2015; Held, 2006; Pettersen, 2012). At this point, knowledge of children's expressed needs may be partial, thus open to communication and negotiation in the giving of care. An ethics of care embraces the unknown and unpredictability of human relations. The deliberation involved in recognizing need is both affective and intellectual, with emotions, thought, and competencies all contributing to the giving of care (Collins, 2015).

In moving from recognition of children's needs to action in meeting needs, the carer must have the competence to act. Careful listening to children's needs, ideas, interests, concerns, and goals communicated in multiple ways without judging, classifying, or fitting them to match preconceptions of the child is paramount (Noddings, 2013). The meaning of children's needs is jointly constructed between educators and children and remains provisional. Choosing dialogical and inquiring communication, rather than monological communication, with children signals to children that they are active participants in their care (Pacini-Ketchabaw et al., 2015). Working through what children want often requires time, negotiation of misunderstandings, flexibility, and adjustment. These complexities indicate that the giving of care, infused with ethical decision making, is much more than a technical skill of providing instrumental care. Care in this sense is not a means to an end but rather a value in itself and the ways in which human relations deepen and flourish (Gilson, 2014).

Tronto's final phase of care involves the perspectives of the caregiver and the care receiver on the caring encounter. Including the perspectives of the care receiver is necessary if we are to understand care to be relational. Noddings (2002) states that ethics of care:

asks after the effects on recipients of our care. It demands to know whether relations of care have in fact been established, maintained, or enhanced and, by extension, it counsels us to consider effects on the whole webs or network of care. (p. 30)

In other words, care is completed when we know more about how children feel and experience their care and 
respond to it in varying ways. Moments of completion may involve multiple modes of communication such as bodies, language, and emotions. Talking with children about their care may require more dialogue and inquiry, with room for fluidity and change in the educator's response to a child's response to care. Children's responses inform future caring interactions and relationships between educators and children.

Integral to the processes of care is an acknowledgment that care relations are asymmetrical in terms of need and ability to exercise power (Held 2006). Therefore, the care of young children requires an ethics to highlight the unequal relations between educators, who typically hold power, and children, who do not. The more power exercised by the educator in caregiving-in Nodding's sense and often evident in paternalism and teacher direction-the more likely it is that the possibility for ethical care will be diminished. However, educators cannot separate themselves from embodied and subjective experiences of their social locations and the inequities in the political and policy contexts in which their care is practised. Therefore, educators need to critically reflect on their subject positions, their power and lack of power, and their strengths and limitations in caring interactions.

\section{Observations}

\section{Methodology}

The study involved non-participant observation of care practices in a naturalistic setting: preschool rooms in two different childcare centres. Nonparticipant observation is used in research situations in which the observer is not involved in the activities being observed (Liu \& Maitlis, 2010). In conducting the observations, we aimed to identify and explore the complexities of care. We brought to the observations our own experiences with caring for others and being cared for and our reading of ethics of care literature. The two selected childcare centres are part of multiservice agencies with unionized staff. Each preschool room could have up to 24 children with a staff-children ratio of one to eight. Observations by two researchers (one principal investigator and one research assistant) were conducted in the selected preschool rooms on the same morning each week from approximately 8:30 to 10:30 for four weeks. It was anticipated that observing a preschool room multiple times in two different sites would deepen an understanding of the complexities of care practices. Once all observations were concluded in one centre, a second set of observations commenced at the second centre. Prior to conducting the observations, research consent was obtained from educators, parents, and children. Children were asked if we could write down (the observation tools were shown along with a picture of where the observers would sit) "what they did with their teacher." Children provided a yes or no answer. When possible, we discussed our interest in the challenges of care and care work in the early childhood education field with the educators prior to conducting the observations. All the educators consented to being observed; only children who both consented and had parents who consented were observed. As will be described later, some educators were the sole adult in the program room for most of the observation period; other educators came into the room sporadically to assist with transitions.

One objection to these observations may be that they are narrowly focused on a human dyad and do not capture all the possibilities of care in an early childhood program. However, we argue that interactions between educators and children matter. They matter to educators who hold caring values in relation to children and they matter to children who directly experience the presence or absence of caring encounters. At the same time, we agree with Tronto's (2013) rejection of a dyadic understanding of care because, as Tronto argues, care transcends the personal into the policy and political realms. In concrete terms, educators' caring practices at the interpersonal level can be significantly constrained when early childhood policies and politics do not take care seriously.

In order for the researchers to be open to the complexities and challenges of caring well in an early childhood program, templates or observational coding sheets were not used. However, we wondered if, in our analyses 
of the observations, we would discern processes associated with care ethics such as attentiveness, compassion, responsiveness, sensitivity to contextual variations, and dialogical communication between educators and children. We were also interested in how the observations might illustrate the completion of care, Tronto's (2013) final phase of caring that embraces children as active participants in their care. The observers were trained to write by hand independent, detailed, and objective running records on all spontaneous or planned (in the case of group time) interactions between the educators and children. The fundamental premise behind all the observationswhether they were concerned with children's bodies, emotions, or minds-was that every interaction had the potential to be caring. In focusing on an interaction, we sought to reveal the relation between individuals and, within that relation, the nature of the care. The observation notes captured the following: the beginning and end of an interaction, how the educators and children talked and behaved together, contours of talk (intonation), and emotional states and body behaviour (e.g., facial expressions and eye gaze).

Immediately upon completing each observation session, the two observers met, compared points of similarities and differences in field notes, discussed these points in relation to an understanding of care ethics, and wrote additional analytic memos. Our aim was to produce thick descriptions of care practices. We acknowledge the limitations of our methodological approach. We were not able to adequately explore educators' perspectives on their care decisions and interactions with children or children's perspectives on their care. We were thus limited to interpreting care practices, and responses to them, at the time of the interaction. We also recognize that our observations, conducted in only two early childhood centres, are not necessarily a comprehensive reflection of care practices in all Canadian early childhood settings. We were explicit in approaching these two centres in that they both had unionized staff and administrative support from larger organizations. In this way, we hoped these centres would be positioned as well as possible (within a fundamentally market system) to encourage ethical care interactions.

\section{Findings}

Three themes emerged from an analysis of the observation data. First, the care interactions observed between the educators and children can be described as instrumental. Second, the interactions the educators had with the children were frequently interrupted and therefore brief. When lengthier interactions appeared possible, they were disrupted when the educators needed to direct their attention elsewhere. Third, the children's participation in the interactions was typically limited. Each of these findings, supported with concrete examples from the observations, will be described and discussed below. In reporting on our findings, we are aware that we are both interpreting and evaluating the practices of the observed educators in relation to an ethics of care. We faced a difficult, ethical dilemma as to whether publishing our findings would be helpful for early childhood educators and the sector more broadly because, as the findings reveal, for the most part, we did not see the practice of ethical care. Our intention is to always honour the work of early childhood educators, who we trust are doing the best they can with little structural supports. In the end, we felt that it is important to describe the care we found in our observations and to assert that structural factors and the devaluation of care rather than the personal limitations of the educators shaped the nature of the care given. As Selma Sevenhuijsen (1998, p. 151) remarks, "how we can care depends to a great extent on how we give shape to our society." Conversely, the priorities of societies dictate the possibilities for caring relations in everyday settings.

\section{Instrumental caregiving}

Many observed interactions involved educators assisting children with dressing, toileting, eating, cleaning up, self-regulating, sharing, resolving conflicts with other children, and choosing activities. The actions of educators in these interactions can be described as instrumental in that the action of assistance was the means by which the 
interaction was completed. The examples below illustrate this instrumentality in which the children's independence is the end goal.

A child has sand in her boots and expresses her frustration. The educator crouches down, asks, "Where are your shoes?" and then says, "Sit down. I'll help you." The educator helps the child dump out the sand and put her boots back on. The educator says, "Ask mommy to bring shoes-it's too hot for boots."

The educator hugs and then directs a child to the washroom. She says, "Dad says you are going pee and poo in the toilet. No more diapers. Can you try going to the bathroom now?" The child runs away from the bathroom. Later the educator tells the child, "Superheroes don't use diapers. Superheroes go to the toilet."

Two children want to play with the same toy. The educator addresses one child, saying, "You need to talk to [other child]." The child says, "I need it." The educator responds, "It's not 'I need it.' You need to wait your turn."

Interactions in which the educators and children came together for songs and stories accelerated instrumental management of the children's behaviour. The children were required to "keep hands to themselves," "sit down," "keep their eyes on me", and "listen." In other interactions, the children's interests were first acknowledged and then managed. For example, an educator tied blankets on some children and said, "We have supermen." She immediately added: "[child's name] walking feet or maybe we need to take the cape away."

Many interactions involved educators assisting children with conflicts as in the following examples:

Two children have a conflict over a toy. An educator asks, "Sharing is what?" Another child says, "Caring." The educator repeats, "Sharing is caring." The children share and the educator asks one of them to say, "Thank you." The child adds, "We're sharing!" The educator says, "Good job."

A child tells an educator that another child is not sharing, saying, "He has too many." The educator and the child approach the child with the toy. The educator crouches and says, "You can share with your friends. There are three sets." The children share and briefly build a tower together.

One practice-intentionally limiting the amount of materials-increased the number of interactions in which the educator was drawn into conflicts between children. For example, an educator introduced one activity: "My friends, I am going to bring only three squeeze bottles. We are going to share." All interactions thereafter involved managing turn taking. When one child wanted to join the activity and have a squeeze bottle, the educator said, "When [another child's name] is finished, you can have a turn." The child left and did not return to the activity.

Program activities set out on tables also tended to be instrumental, with educators soliciting children's cognitive knowledge of colours, sizes, and letters. In one preschool room, most activities required the children to colour or paint, cut paper, and glue or tape things together (stickers, sand, pipe cleaners, and Popsicle sticks). The educators tended to sit at the tables to assist the children and ask questions. The following example characterizes most program activities:

At the art table, children are painting small paper plates yellow. They glue pre-cut black stripes on them. The educator sings the "bumble bee song." Later the educator says to a child, "I love your bee. That's [another child's] bee. What does the bee say? Tomorrow we can add eyes, wings, and mouth." The child says, "Yes."

One program activity offered the possibility of more sustained educator-child interactions focused on the children's needs, interests, and ideas. A basket of books, with one book about princesses, prompted children to 
ask for crowns, which the educator began to make with construction paper and tape. Many children joined in the crown making-boys, too, because "crowns are not just for girls." Children gathered up small triangles cut out of the crowns by the educator for other uses. Other children fetched sheets of paper to cut or rip up to make smaller pieces. However, when the educator left the activity, the children followed, and a clean-up process commenced.

Drawing on these observation examples, the instrumentality of educator responses to children's needs illustrates Nodding's (2015) description of caregiving activities, contrasted with caring informed by the processes of care ethics. Certainly, educators made decisions to respond to children's needs and acted accordingly. However, the brevity of educator-child interactions showed limited opportunities for educators to engage in the complexities of caring, such as listening, inquiry, negotiation, flexibility, and adjustment (Hamington, 2015). The absence of these complexities reinforced the instrumentality of the interactions as discrete exchanges of assistance between an educator and child. The messiness and complexities of care processes - their overlap and interweaving-were not evident in these discrete exchanges. Therefore, the observations indicate that in thinking about care practices in early childhood settings, the focus must not only be on what care is (the caregiving) but also on how the care is given and completed (the caring).

Instrumental caregiving was particularly evident in educator interventions in children's conflicts. For example, the children were directed by the educators to follow classroom rules to get what they wanted. In invoking abstract rules and a technical skill (giving rules), little ethical understanding of the children's conflicts was required. Indeed, several observations indicate that educators misunderstood and mismatched rules with a situation because they did not (or could not) take the time to understand the conflict from the children's perspectives. That said, in some situations observed, instrumental care in the children's conflicts may have been necessary in the short term for the children's safety. However, ethical caring can follow instrumental caregiving when educators and children work together on resolving the situation that provoked the safety concern.

Similarly, observed program activities can be characterized as instrumental caregiving designed to meet and assess preschool children's developmental skills and needs. The observation data shows that the simplicity of the program activities did not provide opportunities for more complex processes of ethical care, such as responsiveness to the children's ideas and goals, dialogical communication, and creativity. In addition, educators' decisions to limit the amount of materials to promote sharing (and caring) exacerbated children's disengagement in activities and/or increased conflicts between children. This pedagogical choice then required more instrumental caregiving from the educators to manage disengaged children and conflicts between children. Together, these findings suggest that there is an association between the complexity of a pedagogical activity and the depth of ethical care possible.

\section{Care interrupted}

We observed a higher-than-expected ratio of children to educators. In Ontario, a provision in the Child Care and Early Years Act 2014 allows for reduced ratios when children are arriving, leaving, or during the rest period. For programs that run for six hours or more in a day, a staff/child ratio may be reduced to two thirds of the required ratio for up to 90 minutes after the program starts each day. Consequently, in the two preschool rooms observed, from 9:00 a.m. to 10:00 a.m., a single educator could be with up to 18 children. With this number of children, the educators were observed simply trying to stay afloat and maintain the safety of the children. Observation notes from one particular morning (see below) show an educator moving from area to area every couple of minutes, the children flitting from activity to activity, and the room getting messier and messier, which then required the educator to devote more time to cleaning up.

In the block area and with hammers and cardboard tubing, an educator briefly plays with a child whose 
arrival has been difficult. The educator leaves to clean up the dramatic play area. The child calls out to the educator from the block area, showing her two hammers. The educator says, "That's my hammer. I will come in five minutes. I am coming back. Save my hammer." The educator continues to clean up the dramatic play area. She returns to the block area and briefly plays with the child and the hammers. Later, when the child follows another child shaking the hammer, the educator says, "I understand that you want to play with [child's name], but she's not going to want to play with you if you do that." The educator gets a book to read with the child. Other children join the book reading.

Another episode shows how the educator's capacity to sustain caring interactions was interrupted by other demands:

The educator and several children are at the art table with some paper and trays. The educator asks, "What are you making? A rolling pin?" Some children roll up the paper. The educator asks, "What do you need to put it together?" The children say, "Tape." The educator puts on music, and then leaves the art table to deal with an issue. The children do not have the tape. They put trays on their heads. The educator says, “I don't think you are ready for tape." Later, the educator gives the tape to the children.

Observations of the children's behaviour revealed that the constant interruptions in their interactions with educators affected them. Some children repeatedly tried to get the educator's attention but, absorbed in managing other problems, the educator often missed the children's calls. On occasion, an educator multitasked, responding to a child's call from a distance while continuing to do something else. In some cases during the observation period (approximately two hours), certain children did not experience any interactions with an educator. In other interactions, the educator's recognition of children's needs was disjointed.

A child calls to an educator from the art table, "I made this sword." The educator asks, "You made it? How did you make it?" The educator suddenly turns to help with a conflict. The child does not respond to the questions. Later, the educator and the child pretend to talk on the phone with each other about going to the supermarket. Later, the educator asks the child, "What should we put on the art table?" The child says, "Pipe cleaners," but does not continue with the activity.

As observers, we were deeply concerned about the educators' struggles to be responsive to the children. We could see that the educators had caring values and sought to be caring. However, structural factors clearly constrained their care practices. In particular, insufficient staffing levels meant that the educators scrambled to respond to the children's needs and to provide adequate time for meaningful and deeper caring actions. Our observations poignantly show that when structural supports are not in place, the potential for caring is diminished. Barnes (2012) captures how even in the best of times ethical care is difficult to practice:

[Ethical care] requires not only an emotional and ethical sensibility, but the capacity to understand different personal, economic, social, and cultural contexts; to read particular responses to acts of care; and to draw from diverse sources and types of knowledge to make good judgments with others about the right things to do in situations that may be messy, confused, and changing. And this has to be done in situations where there may be conflicts between caregivers and receivers, and between different caregivers; where paid care workers may feel unsupported or that they are operating in a policy context that does not reflect the values of care (p.172).

\section{Care incomplete}

Our observation notes reveal it was most difficult to ascertain children's participation in interactions with educators. After the first week of observations, we carefully watched for verbal and other modes of communication that could, at least partially, indicate what the caregiving or caring meant to children. Some examples show children's 
satisfaction with an educator's response to their needs. An educator comforted a crying child and said, "You know that I made a ball [from playdough]. You try it." The child stopped crying and made their own playdough ball. On other occasions, particularly with more verbal children, educators recognized a child's need, interest, or goal, and the child acknowledged this recognition. For example, when an educator began to clean up the art area, a child told her that she had not done the art activity. The educator suggested the child could set up the activity in the afternoon. The child replied, "OK."

However, our observations of interactions between the children and educators, from playing with hammers to donning superhero capes, illustrate an overall denial of children's experiences of "care." The observation data points to three reasons for children's lack of participation in their own care. First, the instrumental nature of the caregiving did not leave any room for children's responses, as the following example shows:

Two children run into each other. One child explains what happened to an educator. The educator says, "You do not hit your friend. If your friend falls, you help pick them up. Superheroes, do they help people or hurt people? You need to help; otherwise you are not a friend." The educator takes the superhero scarf away from the child. The child hugs a stuffed animal and walks away. The other child continues to play.

Children were not asked if, for example, solutions to conflicts or problems helped and/or satisfied them. Sometimes in a conflict an educator would instruct a child to say sorry to another child, but the children's responses (saying sorry) were not spontaneous.

Second, the brevity of educator-child interactions did not allow any time for the children to respond to the caregiving. Many educator-child interactions were interrupted by something else happening in the room, as in this example:

An educator says to a child, "Do you want to paint? What colour do you want?" The child looks at the paint and points to yellow. The educator suddenly notices another child running with a stroller, and says, "Careful! Do you need a baby for your stroller?" and does not see the first child pointing to a colour. The child says, "I want yellow." The educator walks to another area.

Finally, our observation data suggests that the instrumental goals of the educators' responses to needs discouraged children from talking about how they felt about the care given. Particularly when staff-child ratios were high, the goal was to return the children to a state of safety and positive feelings. Taking time to discuss with the children their perspectives on the care received would have been contrary to this goal. For example, in one observed interaction (during group time), a lesson in children's safety was prioritized over exploration of emotions:

An educator reads a book about "being mad." The children show their "mad faces." At the end of the story the main character says, "He might wait to run away until tomorrow [now that he isn't so mad]." The educator states, "It's not safe to run away from mommy and daddy." The children say, "No." The story ended.

The prioritizing of safety and suppression of negative emotions were also evident when children expressed strong emotions and resisted educators' instrumental caregiving, as in this example:

A child repeatedly hits another child with a phone. While tending to the hurt child, the educator says, "Last chance" to the other child, who responds, "I'm not going to talk to the teacher anymore. is rude and I don't want to talk to her anymore." The educator asks the child, "Do you want me to talk to Mommy?" The child spits at the educator, who says, "All done. Excuse me!" The child starts to cry. The educator tells her, "It's OK to be upset, but it's not OK to hit your friends." Later the educator asks 
the child why she hits her friends and tells her she cannot spit on a teacher's face. The educator asks the child if she understands. When the child does not respond, the educator asks her to say, "Yes, [educator's name]."

On many levels, this last example underscores the difficulties the educators and children experienced with caring ethically in contexts that were frequently not conducive to supporting care relations. The educators appeared to have a clear expectation of what the children needed-or should need-lacking the time to negotiate with them what they themselves perceived they needed. Working in difficult conditions, the educators appeared to expect the children to receive "care" passively with little resistance or questioning of the "caring" interaction. In this way, the children were rarely able to complete their care, having little opportunity to acknowledge how, or even if, they had experienced care. In denying the children the opportunity to be active agents in their own care, the competency of both the children and the educators was undermined. It could also be argued that the educators were denied the opportunity to engage in caring practices consistent with their values as educators. It is unarguably very difficult to complete care encounters when simultaneously attending to multiple other (often urgent) demands. Thus, the educators did not experience care themselves, which denied them the structural conditions necessary to care well.

\section{Discussion}

In our study, we observed many, among hundreds, of ordinary moments in early childhood settings in which educators and children interacted. We were not interested in applying any technocratic approaches or developmental theory vis-à-vis, for instance, behaviour guidance strategies to understand these educator-children interactions. We wanted to go beyond the assumption that care is implicit in the work of early childhood educators. From an ethics of care perspective, care is understood as a set of valuable processes within complex power relations, rather than a means to an end in which the caregiver exercises power over the care receiver. We considered how care relations represented responsiveness from both the caregiver and care receiver, sensitivity to context, and emotions as motivating ethical resources (Engster \& Hamington, 2015). From our perspective, all interactions in all activities, whether they involved removing sand or a painting, have the potential for ethical care. It is not the activities in the early childhood setting per se that are significant for an ethics of care and create meaning (or not) for those involved, but rather the processes involved in human interactions.

Our study indicates that an ethics of care was typically absent in observed interactions. Rather, interactions were instrumental in nature and the children passively received and/or rejected the care. Because instrumental care is a dominant way of understanding care across Western, English-speaking nations, it is fair to ask whether the instrumental care we observed is common in Canadian early childhood settings. Our observations offer insights into how children experience such instrumental interactions with educators and also the practical challenges for educators who hold caring values but struggle to provide ethical care experiences with children (and for themselves) amid constantly competing priorities.

It became apparent during our observations that the educators experienced frustration in their interactions with the children, particularly when the children did not receive "care" as the educators had intended. While the educators communicated caring values in interactions with the researchers, there appeared to be a sense of alienation from these values in their interactions with the children. Simply put, the educators were not able to practise the caring values they held within the sociopolitical context of their practice. While we recognize that the educators have some agency to be caring in conducting acts of caregiving, the number of children in need of care at any one time made it near impossible for this to consistently occur. There was simply no time or space to receive a child into their "centre of being" (Noddings, 2015, p. 77) and respond in thoughtful, open, and compassionate ways given the simultaneous competing needs of several other children in the room. This may lead an educator to feel incompetent, unable to 
adequately engage with the children and the complexities of care. It is further possible that the educator's feelings of powerlessness may lead to a greater assertion of power over the children through instrumental interactions. The powerlessness of the educator is heightened by the oppressive socioeconomic conditions under which educators attempt to practise ethical care. Therefore, we cannot hold educators solely responsible for the outcomes of our observations. Indeed, we seek to avoid making educators personally responsible for the problems in ECEC. The state of care in early childhood programs is a systemic problem in need of a systemic solution.

Our observations raise questions about not only the ethical nature of care in practice, but also the necessity of situating care practices within a sociopolitical context. Barnes, Brannelly, Ward, and Ward (2015) argue that "Recent years have witnessed multiple evidences of the failures of neoliberalism" (p. 7). The observed absence of an ethics of care in early childhood settings is one such failure. While neoliberalism purports that work can be made more "efficient" (i.e., raising staff-child ratios during certain times), this logic simply does not apply to the practice of good care. As stated by Tronto (2003), "little in caring can be enhanced by being forced in a time/space compression" (p. 123). Therefore, the structural inequities at the sociopolitical level have concrete consequences for the care experiences of children and educators in early childhood settings. On a very basic level, there needs to be a sufficient number of educators to address the constant, changing, complex needs of children. Similarly, there needs to be space for educators to feel supported, valued, and heard by those who create and produce the structures and policies that undermine their caring practices. In Eva Kittay's (2015) care-based conception of justice, those who care for others in the human condition of inevitable dependency and interdependence must be protected from "exploitation and deprivation of resources and opportunities" so that they can care well (p. 63).

The question therefore becomes: Is there an alternative? It seems that educators and children alike want more care in their interactions with each other. Furthermore, to address power imbalances in care relations, children's participation in their own care is ethically significant. At a political level, Tronto's (2013) vision of a caring democracy is helpful in that it seeks to position care as the central organizing feature of society. If this were the case, institutions and structures would encourage the systematic support of care ethics in early childhood practice. Even within the existing neoliberal political climate, however, we argue that educators can collectively begin to resist the unrelenting neoliberal drive for technocratic instrumental caregiving in early childhood settings. It is possible that, in care relations between educators and children, complexity, difference, and an openness to uncertainty, unpredictability, and wonder are encouraged and embraced, even within difficult working conditions (Moss, 2017, p 20).

At the same time, if we value care relations and understand the purpose of care differently, some of the structural barriers to caring ethically can begin to be addressed. For example, staffing could be reconfigured in a way more conducive to an ethics of care. While we acknowledge that the number of educators may be limited (although they should not be) by economic resources (and the sociopolitical climate), it may be possible to create greater cohesiveness and collective responsibility for each other within a centre through bridging existing group / room divisions. Full-time educators could be systematically encouraged to engage with all the children in a centre (rather than only their group/room), thus fostering stable, continuous care relations in circumstances where more educators are needed. In addition, in contrast to the observed sporadic delivery of instrumental care by less familiar early childhood educators, educators could engage full-time (or at least consistently) with the same children. This would support the conditions necessary for meaningful, ethical care work. Similarly, it is possible to address the systemic isolation of educators through both acknowledging this isolation and engaging in democratic conversations around the complexities of caring well. When we have the space and time to critically engage with care ethics and identify the barriers to it, we move toward realizing a vision and practice of caring well in early childhood settings. Moreover, when educators are valued discursively and materially as attentive, responsible, 
competent, and responsive citizens, we will begin to build a democracy that is truly caring (Tronto, 2015).

\section{Acknowledgments}

We wish to acknowledge Jacqueline White for her involvement in the project, particularly her ability to push our thinking regarding what caring relations mean and look like on a practice level. We also thank anonymous reviewers who helped us think through ways to communicate our findings. A Social Sciences and Humanities Research Council of Canada grant supported the research described in the article. 


\section{References}

Barnes, M. (2012). Care in everyday life: An ethic of care in practice. Bristol, UK: Policy Press.

Barnes, M., Brannelly, T., Ward L., \& Ward, N. (2015). (Eds.) Ethics of care: Critical advances in international perspective. Bristol, UK: Policy Press.

Collins, S. (2015). The core of care ethics. Basingstoke, UK: Palgrave Macmillan.

Dahlberg, G., \& Moss, P. (2005). Ethics and politics in early childhood education. London, UK: Routledge.

Daly, M. (2012). Making policy for care: Experience in Europe and its implications in Asia. International Journal of Sociology and Social Policy, 32(11/12), 623-635. https://doi.org/10.1108/01443331211280674

Engster, D., \& Hamington, M. (Eds.) (2015). Care ethics \& political theory. Oxford, Oxford University Press.

Gilson, E. (2014). The ethics of vulnerability: A feminist analysis of social life and practice. London, UK: Routledge.

Hamington, M. (2015). Politics is not a game: The radical potential of care. In D. Engster \& M. Hamington (Eds.), Care ethics and political theory (pp. 272-292). Oxford, UK: Oxford University Press.

Held, V. (2006). The ethics of care: Personal, political, and global. Oxford, UK; Toronto, Canada: Oxford University Press.

Kittay, E. (2001). A feminist public ethic of care meets the new communitarian family policy. Ethics, 111(3), 523-547. https://doi. org/10.1086/233525

Kittay, E. (2015). A theory of justice as fair terms of social life given our inevitable dependency and our inextricable interdependency, In D. Engster \& M. Hamington (Eds.), Care ethics and political theory (pp. 51-71). Oxford, UK: Oxford University Press.

Langford, R. (2019). Theorizing feminist ethics of care in early childhood practice: Possibilities and dangers. London, UK: Bloomsbury Academic Press.

Liu, F., \& Maitlis, S. (2010). Nonparticipant observation. In A. Mills, G. Durepos, \& E. Wiebe (Eds.), Encyclopedia of case study research (pp. 610-612). Thousand Oaks, CA: Sage Publications.

Löfdahl, A., \& Folke-Fichtelius, M. (2015). Preschool's new suit: Care in terms of learning and knowledge. Early Years, 35(3), $260-272$. https://doi.org/10.1080/09575146.2014.995600

Luff, P., \& Kanyal, M. (2015). Maternal thinking and beyond: Towards a care-full pedagogy for early childhood. Early Childhood Development and Care, 185(11-12), 1748-1761. https://doi.org/10.1080/03004430.2015.1028389

Moss, P. (2017). Power and resistance in early childhood education: From dominant discourse to democratic experimentalism. Journal of Pedagogy, 8(1), 11-32. https://doi.org/10.1515/jped-2017-0001

Noddings, N. (2002). Starting at home: Caring and social policy. Berkeley, CA: University of California Press.

Noddings, N. (2013). Caring: A relational approach to ethics and moral education (2 $2^{\text {nd }}$ ed.). Berkley: University of California Press.

Noddings, N. (2015). Care ethics and "caring” organizations. In D. Engster and M. Hamington (Eds.), Care ethics and political theory (pp. 72-84). Oxford, UK: Oxford University Press.

Pacini-Ketchabaw, V., Nxumalo, F., Kocher, L., Elliott, E., \& Sanchez, A. (2015). Journeys: Reconceptualizing early childhood practices through pedagogical narration. North York, Ontario: University of Toronto Press.

Papatheodoru, T. (2009). Exploring relational pedagogy. In T. Papatheodoru \& J. Moyles (Eds.), Learning together in the early years: Exploring relational pedagogy (pp. 3-17). London: New York: Routledge.

Pettersen, T. (2012). Conceptions of care: Altruism, feminism, and mature care. Hypatia, 27(2), 366-389. https://doi.org/10.1111/j.15272001.2011.01197.x 
Randall, T. E. (2018). Values in good caring relations. Feminist Philosophy Quarterly, 4(3), Article 4. https://doi.org/10.5206/ $\mathrm{fpq} / 2018.3 .5781$

Robinson, F. (2011). A feminist approach to human security. Philadelphia, PA: Temple University Press.

Sevenhuijsen, S. (1998). Citizenship and the ethics of care: Feminist considerations on justice, morality, and politics. London, UK: Routledge.

Tronto, J. C. (2003). Time’s place. Feminist Theory, 4(2), 119-138. https://doi.org/10.1177/14647001030042002

Tronto, J. C. (2013). Caring democracy: Markets, equality, and justice. New York, NY: New York University Press.

Tronto, J. C. (2015). Who cares? How do reshape a democratic politics. Ithaca, NY: Cornell University Press.

Van Laere, K., \& Vandenbroeck, M. (2016). The (in)convenience of care in preschool education: Examining staff views on educare. Early Years, 36(5), 1-15. https://doi.org/10.1080/09575146.2016.1252727

\section{Endnotes}

1. We prefer the term "instrumental" over the more commonly used term "custodial." From our perspective, instrumental care more clearly communicates that this care is a means to an immediate predetermined end. 